\title{
THE SPACE BETWEEN THE LINES IS NOT NEUTRAL Pedagogical Labour in Failing Institutions
}

Jemina Lindholm and Kaura Raudaskoski

\section{ABSTRACT}

In this essay we analyze the current status quo of art and cultural institutions in relation to social justice, and how the question of change is inherently pedagogical in nature. Throughout the text, we highlight the need for various feminist pedagogical approaches and nuanced methods that are pivotal in learning, unlearning and dismantling oppressive structures within institutions. We discuss failure as an inevitable dimension of transformative learning and contemplate different pedagogical approaches to disrupting oppression both on institutional and individual level. We do that by addressing the various silences that perpetuate the status quo, and finally ask what it means for art and cultural institutions to become accountable.

\section{ABSTRAKTI}

Tässä esseessä analysoimme taide- ja kulttuuri-instituutioiden nykytilaa suhteessa sosiaaliseen oikeudenmukaisuuteen ja sitä, miten muutokseen liittyvät kysymykset ovat perusluonteeltaan pedagogisia. Tekstissä korostamme tarvetta erilaisille feministisen pedagogiikan lähestymistavoille ja sensitiivisille menetelmille, jotka ovat keskeisiä oppimisessa, (pois)oppimisessa ja instituutioiden sortavien rakenteiden purkamisessa.

\section{People acknowledgement:}

We want to publicly acknowledge that the State of Finland exists partly on Sápmi, the lands of the Sámi people. We pay our respects and show our support to the Sámi people as the indigenous inhabitants of the Sápmi, and we recognize their rights as an indigenous people. We recognise and respect their sovereignty, their culture, their stewardship, and their continuing contribution to the life of this state.

\section{Failing as an institution}

Working in various positions with and within art and cultural institutions in Finland - from working as freelance educators and pedagogues, to working on a monthly salary on projects or in public programs in general, to working as outsourced trainers in social justice and feminist pedagogy in different contexts - we have witnessed that public institutions strive to embrace content involving marginalized people and their experiences

1 This acknowledgement is a tentative example on how to recognize Finnish colonialism while working in Southern Finland, and it has been drafted in collaboration with a group of Sámi cultural workers.
Jemina Lindholm 
as well as initiatives for social justice. The interest is simultaneously very welcome and needed, but it also entails pitfalls that we all should pay close attention to.

The trend to include marginalized perspectives as a subject matter but not as sustainable and transformative practices indicates a mere charitable interest towards these topics or communities, and is simply not enough to actualize changes. The value of such content is too often only regarded as a sign of diversity and progress of a certain institution, which also means that too often public programs that include these perspectives remain as superimposed mentions or annual special happenings during Pride Month or other campaigns. Without actual change and widespread dismantling of the hurtful power structures, this embracing may in reality further assimilation, tokenism and commodification - a fact repeatedly voiced by marginalized communities (Liu 2018, 12-27).

Working in these institutions as queer or crip humans feels contradictory: we are both disappointed and hopeful at the same time. Disappointed that enhancing social justice in these institutions seems to be very slow and often an unfamiliar idea to others working in the same institutions; and hopeful as these institutions still have the potential to work as sites for generating more just practices and as spaces for conversations and societal change.

Even though we are inherently entangled with and navigate these issues from our multiple positions, we have to admit that it is hard to recognize or locate the reasons why social justice and enhancing marginalized voices seem to be something that most institutions are rooting for but, at the same time, fail to take necessary actions. These contradictions seem to be thoroughly pedagogical as they involve questions of learning social justice, learning intersectional feminism, and unlearning oppression.
In the light of the insufficient efforts of the institutions to dismantle inherent oppression and the subsequent commodification of marginalized identities, we want to bring forth the failure of social justice advancement in arts and cultural institutions. In our experience, this failure is currently the status quo in the institutional environment in Finland. Arts and cultural institutions seemingly aim at just practices and diverse programming, but continuously thus failing at taking the necessary last steps in really listening to people they are trying to engage, fail at operating responsibly or being accountable when being in the wrong or making mistakes.

We also need to point out that we are constantly failing as well: failing as (freelance) pedagogues, failing as workers, failing as parts of institutions to engage in feminist work although we are feminists. Why is this, and why is it so hard to be a feminist in an institution? Why are so many feminists overwhelmingly tired, worn out, or "closeted" as feminists at their workplaces? One possible answer is that this kind of failure is in reality not about the individual failing to follow their own values but rather the institution failing us in not providing emotional, moral, ethical and strategic support or in not carrying out the necessary changes to accommodate social justice. In our experience, almost all of the structural social justice initiatives are done by freelance and part-time workers with poor terms and conditions of employment, and this work is overwhelmingly often unpaid. This indeed reminds of the queer and crip aspects of failure (Halberstam 2011; Mitchell and Snyder 2016, 37-53; Oakley 2018, 6-11), which regard failure as an inevitable necessity in an oppressive and socially exclusive environments, where no other option than to fail is open for those who wish to change things or remain as unmolded as possible by cis-heteronormativity, ableism, racism, or other oppressive hegemonies. In a failing institution, these oppressive traditions live on and thrive as there are few supporting structures for efforts to disrupt them. 
In this context, we need to look closely at what an institution actually does and what does it mean for an institution to fail. In most institutional critique over the past 30 years, institutions are seen as part of a larger environment where institutions affect each other in various ways (Powell and DiMaggio 1991). This is called institutional peer pressure, and it drives the goals of economic success and institutional legitimacy, i.e. the need to be associated with being current and trustworthy. The peer pressure may be the reason why museums, for example, jump at the opportunity to tap into popular content and practices that have been successful in other institutions. Logically, this has lead to a culture of imitation and conservatism instead of building institutional cultures that are in mutual conversation with the broader and more diverse cultural environment, let alone subcultures that are marginalized in Finland, such as queer and crip communities or communities led by people of colour or Sámi people.

Our critique, then, is aimed towards the unjust operations that such institutional peer pressure makes possible in arts and cultural institutions, and especially in museums: as museums have tried to evolve towards more participatory, equal and open spaces, they have simultaneously maintained the overriding norms of economic success and peer legitimacy which, in reality, hinder the social justice based intersectional feminism ${ }^{2}$ to enter and shape museums. This has led to museums proclaiming to be "for everyone" while they fail to see that their "everyone" is quite an exclusive category. Many museums might be afraid of losing their institutional legitimacy if they actually were to be equally open to everyone, including the feedback and critique that this openness would entail.

2 We understand social justice as the idea of all-encompassing transformative fairness inside society, and also as the structural change enabling as equal distribution of wealth, opportunities, and privileges as possible. This is the premise of the kind of intersectional feminism that we mean by the word "feminism".
This failure to accommodate social justice at the expense of institutional legitimacy is of course embarrassing, in the sense that many of us who are working in museums actually want to promote equality, to change things for the better and open up museums to be more feminist, transformative and political places. Somehow it seems that this collective shame over failing at accommodating actual change has also been institutionalized to a certain extent, as museums strive for credibility in the eyes of a supposedly critical visitor as well as colleagues, but as a result, end up creating content that still does not acknowledge that the museum itself is not a neutral space ${ }^{3}$. Just as Therese Quinn describes in School: Questions about Museums, Culture And Justice to Explore in Your Classroom, museums have a history, and as memory organizations, they are already political to begin with (Quinn 2020, 63-65). This is still not generally understood or accepted: while working with value strategies in Finnish museums, we have witnessed that people who have worked for a long time in executive positions in museums regard many Finnish museums as non-political because they are younger institutions than the internationally recognized Central European museum giants. Some try to justify this view with the fact that Finland is not seen as a settler colonialist state (which it is, see for example Ranta and Kanninen 2019), a common misunderstanding that is based on the fact that Finland did not occupy overseas colonies. However, this exceptionalist argument

3 \#MuseumsAreNotNeutral was a campaign in 2017 initiated by LaTanya Autry and Mike Murawski to refuse the myth of neutrality that many museum professionals and others put forward. They further contemplate on the campaign as follows: "Some people routinely state that museums should be neutral or that museums can't be 'political.' As museums are cultural products that originate from colonial enterprise, they are about power. They are political constructs. Their ongoing practices also are rooted in power. The very fact that this field has a long history of excluding and marginalizing people of color in terms of selection, interpretation, and care of art and other objects, jobs, visitor services, board representation, and more indicates that museums are political spaces. Everything in them and about them involves decisions." (Autry and Murawski 2018.) 
fails to recognize the various, sometimes subtle ways that more recent colonialism, nationalism, commodification, and assimilation operate, and how museums as memory organizations are often complicit in these processes by virtue of their own ideological history (Kostet 2010). But can institutions learn to think differently?

\section{Towards Transformative Pedagogies}

In pointing out that unlearning oppression requires vast pedagogical efforts, a central question often is: what are these efforts, by whom and for whom they are for, and why? We often find ourselves using our pedagogical efforts to educate the institution in which we are working about social justice, and the institutional conventions drain a lot of resources that could be used to directly benefit the marginalized.

What kind of pedagogies would it take for an institution to unlearn oppression and become socially more sustainable? Trying to resolve that question, we have found it useful to distinguish different pedagogies used in different contexts. For us, the typology of anti-oppressive education by North-American educationist Kevin Kumashiro is quite relevant in conceptualizing this.

Kumashiro identifies four types of anti-oppressive education. First is the "Education for the Other", which comprises practices that aim to improve the experiences of the marginalized people. The second type, "Education of the Other", focuses on educating people about the experiences and perspectives of the marginalized instead of carrying on as if there were no problem of oppression in the society. The third type, "Education that is critical of privileging and othering", exposes the inequalities by focusing on structures that create privileges to some but marginalize others. "Education that changes students and society" is the fourth pedagogical approach, and it regards oppression as a discursive practice that perpetuates inequality in often implicit meanings. (Kumashiro 2002, 31-76.)

Often good feminist pedagogical practice needs to handle all of the approaches mentioned above in appropriate situations and with people in different positions. In our diverse work in museums, we focus and aim at providing a platform for "education for the Other" and "education that changes the museum visitor and society" (types 1 and 4), in particular while working as museum educators. But as mentioned above, we end up providing education for our working communities, emphasizing thus "pedagogy that educates about the Other" and "education that is critical towards privilege and othering” (types 2 and 3). In many Finnish cultural institutions, it seems there is not enough knowledge about societal privileges and inequalities that museum work involves, and that only a few people recognize advancing social justice as an obligation by virtue of their job. The need for a feminist pedagogical interventions to change workplace cultures and the need to pay someone to facilitate that tend to stay unrecognized on an organizational level. Salaried people working in executive positions inside the institution are the gatekeepers who have the power to realize structural changes and whose job it is to do so. However, in real life the collegial training work comes as an unpaid addition to the job descriptions of the contracted workers.

As unlearning and change seem to be shameful and scary processes, additional facilitation and resources are needed. We wonder how an institution would work with designated community pedagogues whose responsibility it would be to facilitate these learning processes and hold the institution accountable - and who would get paid for this work. We cannot stress enough that this cannot be done by a single person in an institution, so we literally call for many feminist pedagogues (with different standpoints) for this job as this is draining emotional labour and requires$$
\text { . }
$$ 
high pedagogical skills and intersectional approach. It is draining to recognize, facilitate and witness the moments of crisis (i. e. defensiveness, resistance, agitation, disbelief) in the learning processes, be they individual, communal or societal — and most often they are all of the above. On top of this, the crisis emerges in an environment where emotions and personal perspectives are traditionally dissipated: the workplace. There is also the risk that the work of social justice would simply be outsourced to these community pedagogues while the rest of the working community would just continue the way they have always done.

Nevertheless, no matter how many pedagogues are employed in an institution, in intersectional feminism, failing is still often inevitable. When goals of disrupting oppression and building equality are set high and the structural premises of the society are overwhelmingly capitalist and patriarchal, many efforts may feel insuperable and often leave people working in institutions disappointed and unsatisfied. This is partly due to feminism being an inherently critical movement and the fact that dismantling oppression altogether or establishing equality will never be over and done with. In a neoliberal society, where we expect to see results and impact right away, say and receive our "thank yous" and move to the next issue, the work may feel discouraging and unworthwhile. To a nonfeminist, the constant criticality and the demands may seem like splitting hairs, and one might think: "We already gave you this, what more could you possibly want?" However, the motivation in working for social justice should never be based on praise or prizes; it is commitment to the change without gratification, simply because it is the right thing to do; it is duty before personal or institutional utility. This kind of work can be terrifying at first, and we believe that community pedagogues could help with getting started. After all, there is no other way transformative learning could unfold but through failing, recognizing the shortcomings and becoming internally motivated to change oneself, as personal change precedes organizational and societal change.

\section{Addressing silences}

A lot of institutions are encouraged by the public or activists to do "the work" in order to understand what it is that actually needs to be done to advance social justice. We ponder on what should and could be done to prevent institutional failure (assimilation, tokenism and commodification) and instead actualize the change that would be needed in order to truly support social justice and equality. How can institutions show allyship, and where should they start the work? The fact remains that there are a lot of silences that should be broken, worked on and taken seriously, in order to dig deeper into these problems, or even to recognize that there are problems in institutional practices and attitudes to begin with. These silences have been brought to light in public discussion especially during the year 2020, see for example a Facebook thread iniated by performance artist, writer and teacher Niko Hallikainen (2020), on the striking institutional silence in Finland on Black Lives Matter -movement. It must also be mentioned that such silences are not always coincidental and that there are actual oppressive, widespread, and deeply internalized conventions that actively produce silence, such as exclusive professionalism, anti-queerness, antiblackness and classism, to name just a few.

Our approach is critical, and that is often misunderstood in such institutional contexts that shun un-marketable and negative emotions. By addressing different kinds of silences we hope to open up fruitful and important discussions in a way that would really facilitate change towards real anti-oppressive structures. This is what we call feminist pedagogy.

\section{Strategic silence}

Museum and public institution strategies are full of beautiful language such as "societal impact", "thought provoking", "diverse", "inclusive" and so on. The obvious beauty of these words is that they are more often than 
not left undefined, which allows everybody to fill them with their own projections of what they entail in practice. This leaves the actual meaning and implied values most often undiscussed. Hence one might understand "societal impact" as alt-right-populist steps towards fascism while another understands it as radical anti-oppressive steps towards social justice and liberation. The truth is that without discussion, strategic punchlines can mean whatever. This kind of strategic silence - a central tool in everyday liberalism - allows us to work side by side without ever truly knowing what others actually think, need, want or dream of. More broadly, this means that institutions with strategic silence are not really taking any stances while still claiming to be "thought provoking", "brave", "diverse", or "inclusive". In that case, "everything for all" yet again seems to be "nothing for nobody".

Importantly, this leads to a norm where the professional communities dissipate their values by either actively or passively making them opaque. How is it possible to hold institutions morally accountable for their actions and promises, if we do not know what their core values or responsibilities are or what it means for an institution to act according to those values and responsibilities? It seems that the value discourse has been thoroughly commodified in many cases, meaning that values are only discussed as an instrumental part of marketing. Institutions and working communities should have an urgent responsibility to map out their values and communicate them internally as well as to others in as much detail as possible: What kind of societal impact are they aspiring to and why? What kind of thoughts do they want to provoke, how and why? How do they want to be diverse, and who do they want to include, and why? If this is not done, it leaves no other option than reading between the lines and trusting the institution - and that space in between the lines is certainly not neutral.
In our work as feminist practitioners within museums, a frequent problem has indeed been internal communication: while some working within the institution understand the significance for a cultural institution striving towards equality, there remain considerable gaps in mutual understanding of the necessary actions. This is especially alerting while engaging in pedagogies and practices that are meant to enhance the safety of the marginalized, such as gender-neutral bathrooms and labelling the museum as a discrimination free zone, for example. It is irresponsible for an institution to claim these labels at the expense of the marginalized without doing the very best they possibly can to fully accommodate the people they are "embracing" by doing so. This requires extensive internal (value) discussions with everyone in the organization's working community, a platform that focuses on debating on the core values of the institution, verbalizing them together, discussing differing opinions and arguments, gathering and welcoming critique and feedback also from outside the institution, and facilitating emotional discomfort. If this is not done inside the institution, it will project outside and as a result, the space will be unwelcoming or even hostile to the marginalized. This is one of the reasons why some people never set a foot inside museums.

\section{Emotional silence}

As professional pedagogues, we are very much oriented to thinking about emotional labour and its role in learning, unlearning and defensive resistance to learning, which can sometimes be described as the crisis of unlearning (Kumashiro 2002). Consequently, we have been really struck by the extreme landscape of emotions that surround feminist labour. There are countless cases where providing feminist learning spaces come to a halt because of these emotions, and we have been wondering what they are and what kind of emotional pedagogies they call for. In professional environments, such as workplace communities, it can be hard to open 
discussions about strong discomfort, or fear - let alone shame. The backlash that happens when these emotions are left unattended or are avoided is easily camouflaged and turned into something trivial, or even projected towards the marginalized people instead of seizing the opportunity to introspect and unlearn oppression. Many workplace communities, including arts and cultural institutions, would benefit from training for staff members in working towards distinguishing personal opinions, feelings, and discomfort from what is actually right and good for everybody, especially for people in less privileged positions. Doing "the work", as many intersectional feminist activists say, is a vital element of the learning process. The real emotional challenge is that it can be extremely hard to recognize one's own position in relation to social justice, both inside the institution and as an individual in society at large.

Our pedagogical approach very much relies on this extensive emotional labour. We analyze our own emotions as part of the work, together and individually, and we create a sort of ethnographic space to reflect them before and after the actual working situations, such as workshops, lectures, guided tours or other events. Extremely often we recognize very collective forms of emotions such as anger and being "pissed off", feelings of resistance and crisis, shame and failure, joy and pride. Many of these emotions have a certain role in the dynamics of the situations. Anger is a good example of a complex pedagogical territory that calls for commitment and skill to be facilitated: in the form of "moral outrage" it can play an important role as motivation to change society and fuel feminist work when facing injustices. On the other hand, the dark side of angry emotions is the fact that it is not far away from bitterness, vindictive fury or hate (Nussbaum 2016). We aim to create room for anger in the social situations where we work, as it is hard to manage alone, and more than often it is an understandable reaction to the shortcomings of an oppressive society. In this case, we believe the role of an educator or a pedagogue is to regulate the situation according to their capabilities in order to create room for transformation, be that individual, communal or societal. Previous work done in cultural politics of emotions, notably the works of Sara Ahmed (2013) and Martha Nussbaum (2016), can help feminist pedagogues to analyze the needs for emotional labour in their communities and societies.

\section{Moral silence}

In today's society, it is possible to avoid moral decision-making and responsibility. This is due to the fact that modernist society and culture has taught us that it is possible to live our lives in a moral contradiction, meaning that our actions can differ from our beliefs without us feeling it, or more precisely, witnessing the consequences of such contradiction. Some have described this contradiction as alienation or estrangement.

According to philosopher Tere Vadén, this estrangement is possible in a modern society where a subject is not aware of or does not acknowledge its conditions of life (Vadén 2016, 134-141). The liberal subject refuses to change, as change is a threat to the subject itself, who believes in and lives off its own permanence, individual freedom and increasing possibilities of choices. No amount of piled factual knowledge will enable actual unlearning without other changes in skill, meaning or cognition. Unlearning and change are then possible not with increased rationality but decreased and deconstructed individualism. This takes place when the subject acknowledges its own boundedness and dependency within existence. (Vadén 2016, 134-141.)

This kind of silence, the disconnection or denial of dependency and boundedness, has left the liberal society without moral fibre, as it does not recognize its own preconditions, deeper roots nor material and spiritual interdependence (Vadén 2016, 134-141). When facing a situation where moral decision making should take place, one tends to put their hands up 
all too easily. What kind of work and pedagogies are needed in order to reconnect, align and refamiliarize oneself with these conditions, or in other words, learn, unlearn and change? And what would this kind of unlearning, change and responsibility mean in an institution? One example of how to approach the estrangement within institutional context, as absurd as it may seem, is what we call discussing "death strategy" for the institution: defining what is the lifespan of the institution and its deeper meaning in society, and under what circumstances should the institution stop operating altogether. We have tried this thought experiment in a workshop with people working in various arts and cultural institutions, and overwhelmingly many of them voiced that potential rise of fascism or ultra-commercialism over art and freedom, or their institution's significant contribution to the worsening climate crisis, would justify ending the lifespan of their institution.

The phenomenon of estrangement we discuss here is fundamental to the feminist pedagogical interventions in contemporary arts and cultural institutions. On some level it may be hard or sometimes impossible for an institution to accept that fighting for social justice is at its core anticapitalist work and that social and environmental struggles are caused by these preconditions and deeper roots of our existence, which for the most part are white supremacist, settler colonialist and capitalist - in other words, inherently oppressive. Therefore, intersectional feminist interventions always undermine the status quo and the very foundations of the modern society.

\section{Towards accountable institutions}

Discussions about silences are hard to conduct, yet also vital, since without addressing the silences things cannot change. That is also why, to keep on going, to keep on operating, to keep on keeping on, is often done at the expense of having these discussions, because these discussions prevent and work against silent, pseudo-neutral and valueless action. These discussions are critical and will not let anyone off the hook. In our experience, some people in key positions in arts and cultural institutions are afraid that discussing values openly would steer them away from the core subject matter of the institution. Behind this unfortunate conclusion there is an absurd presupposition that there could be some discrete world of art or culture that would be distinct from society anywhere. Every museum and art institution is inherently involved in society by their very existence, and their silence is active.

Value discussions and discussions about silences frame responsibility and accountability. When stating our values and writing them out, we are letting others know what we are ready to be accountable and responsible for. Given that institutional accountability seems to be a complicated concept for many, it might be useful to define what accountability means for us. This is important as accountability as a term and action is in turmoil in contemporary feminist discourse and the transformative justice framework: we should be asking questions such as what kind of structures being accountable actually requires, how to build circumstances that support accountability, and what to do if an individual or an institution fails at being accountable for their actions. We believe that there is a wide range of nuances in the strategies of holding individuals and institutions accountable, and it always involves real learning, real unlearning, and really confronting the obstacles, be they structural (organizational level) or psychological (personal level).

Writer, educator, and community organizer Mia Mingus (2019) defines accountability as follows:

True accountability is not only apologizing, understanding the impacts your actions have caused on yourself and others, making amends or reparations to the harmed parties; but most importantly,

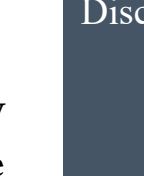


true accountability is changing your behavior so that the harm, violence, abuse does not happen again (Mingus 2019).

Defined this way, accountability is transformative learning. According to Mingus, harm occurs and a process of accountability is needed when an individual acts out of alignment with their values. Thus, it is essential for self-reflection and true accountability that we are clear about the values, as suggested earlier. Without writing out our values and actively reflecting them the practice of accountability is not possible (Mingus 2019). Although Mingus focuses on individuals and small non-institutional settings in their work, we find this framing of accountability useful also while talking about institutions.

While we believe that being accountable is essential, as pedagogues, we are also simultaneously wary of the consequences that call-outs and, more precisely, cancel culture ${ }^{4}$ might lead to, if there is no proper pedagogy involved. Unlearning takes time and emotional effort, and these factors should always be facilitated by insightful pedagogies that support change. One might also pay attention to when, where, in what position and during what period of time one has the capacity of being accountable. The power dynamics are very different if an individual calls out a cultural institution to hold them accountable compared to when a raging twitter mob is harassing a private person with a modest following. The latter, in fact, is not true accountability, because, as Mingus (2019) frames it, also accountability must be consensual. Thus, you cannot force someone to be accountable.

4 "Cancel culture" is a phenomenon where public figures with past oppressive behaviour are "outed" and boycotted or de-platformed in order to restore justice. The dynamics of "canceling" have been criticized from various perspectives, and we see it as pedagogically dubious and risky, aligning with analyses by Kai Cheng Thom (2019) and Natalie Wynn (2019).
How can we call people or institutions out without being ableist (e.g. requiring emotional processes that might break justified personal boundaries) or harmful (e.g. exiling, seeking revenge or punishment, inducing further harm), and simultaneously defend ourselves and demand change? How can we generate real unlearning and keep the conversation nuanced without excusing oppressive behaviour and structures as well as accidentally justifying the silencing of the most marginalized? As writer Clementine Morrigan (2020) puts it, accountability does not mean punishment or humiliation or that we break our own boundaries while being responsible. Asking these questions of course does not justify oppression or cruelty towards any individual, but strives to further enhance the possibilities for unlearning and more just practices and ways of life. While we discuss here the pedagogy required for unlearning oppressive structures within institutions, it is necessary to point out that the oppressed are not obligated to stay calm or patient, nor are they obligated to teach the oppressor. As facilitators of unlearning, we are willing to take on the role of an intersectional feminist community pedagogues. But we also acknowledge that it cannot simply be assumed or forced on an individual, since it involves balancing different personal capacities, extreme regulation of intense emotions, and exposing oneself to possible harm and hurt. Not everybody has the chance of learning as quickly as one would hope.

To be accountable before and after a call-out requires understanding what one is being held accountable for, what one actually did and why it might be wrong. It is impossible to apologize, show remorse or change one's ways if the actions and consequences are not genuinely understood. For example, Nancy Jouwe (2018) writes about oppression within the museum field in relation to colonialism as follows:

[...] the museum, despite great curators and artists, can still function as a violent contact zone for people like me. These are not isolated incidents and it's not just about me; for this is coloniality in practice, 
the everyday utterings of a system. To become aware of this is part of the process of unlearning. (Jouwe 2018, 138.)

Jouwe's text suggests failed accountability in that institutions perpetuate the understanding of colonial practices as isolated incidents that simply went unnoticed by accident. However, the size of the problem is manifested by the accumulation of these incidents and their unproportionate impact on certain groups of people.

As Mia Mingus (2020) points out as well, we need different strategies for working with accountability on interpersonal and institutional levels. An institution does not necessarily require as much compassion or empathy in the process of accountability as an individual does. An institution has always more resources than an individual, which means that change cannot simply be the responsibility of individuals on their own. But as institutions and other communities are formed and led by individuals, both of these levels should be taken into account. To make this process possible, we suggest that institutions should urgently get started with the value discussions, which would enable them to have a common starting point. To end strategic, emotional, and moral silences is a communal process which requires us all to rethink our positions and change our actions, as individuals and as members of institutions. Sadly, it is also possible that an institution, regardless of these discussions, still aims for exclusivity and works in oppressive ways. Through open value discussions, at least some transparency about their underlying conduct would be provided. Conversely, if they are not ready for accountability, superficially embracing the marginalized communities as content or "accidentally" operating in oppressive ways should not be an option. This is probably the most elementary condition for institutional accountability.

Maybe accountability, then, for the people in power positions in public institutions, means having a genuine will to change and unlearn, to engage in critique, debate and feedback without fear, judgement or shame, to continuously acknowledge one's position in relation to others, to step away or give space when needed and also to admit publicly if one cannot or is not prepared to have this conversation right now. This view is especially timely considering the new museum law in Finland which defines the purpose of the museums, among other things, as follows: "to promote community, continuity and cultural diversity; to promote civilization, prosperity, equality and democracy" (Finlex 2019). In our recent work, we have also witnessed these conversations starting to take place, in all their complexity, and this certainly gives us reason to stay hopeful, and no reason for arts and cultural institutions to resist change and stay silent.

\section{References}

Ahmed, Sara. 2013. The Cultural Politics of Emotion. London: Routledge.

Autry, LaTanya and Murawski, Mike. 2018. "Museums Are Not Neutral." Accessed November 9, 2020. https://artstuffmatters.wordpress.com/ museums-are-not-neutral/

Finlex. 2019. "Museum law 314/2019." Accessed August 30, 2020, https://www. finlex.fi/fi/laki/alkup/2019/20190314

Halberstam, Judith/Jack. 2011. The Queer Art of Failure. Durham: Duke University Press.

Hallikainen, Niko. 2020. “Onko kenestäkään muusta tuntunut käsittämättömältä nähdä, kuinka harva kotimainen taidekentän instituutio, organisaatio ja säätiö on ottanut kantaa Black Lives Matteriin viime viikkoina?" Facebook, June 9, 2020. https://www.facebook.com/rotannaama/ posts $/ 1153910181648691$

Kostet, Juhani. 2010. "Onko suomalaisella museolla aatteellista perustaa?" In Suomen museohistoria, edited by Susanna Pettersson and Pauliina Kinanen, 17-27. Hämeenlinna: SKS.

Kumashiro, Kevin. 2002. Troubling Education: "Queer" Activism And Antioppressive Pedagogy. London: Routledge.
SQS

$1-2 / 2020$

Queer Mirror Discussions

Discussions 
Liu, Andrea. "Queer as Refusal And Disidentificatory Act at The Yale School of Art". In Gender Fail - An Anthology on Failure 1, edited by Be Oakley, 12-27. Brooklyn, NY: GenderFail.

Mia Mingus, "Introduction to Transformative Justice," (Zoom Webinar, August 29, 2020).

Mingus, Mia. 2019. "The Four Parts of Accountability: How To Give A Genuine Apology Part 1.” Accessed November 9, 2020. https://leavingevidence. wordpress.com/2019/12/18/how-to-give-a-good-apology-part-1-the-fourparts-of-accountability/

Mitchell, David, Snyder, Sharon and Ware, Linda. 2016. "Curricular Cripistemologies: The Crip/Queer Art of Failure.” Jahrbuch erziehungswissenschaftliche Geschlechterforschung, no. 1: 37-53.

Morrigan, Clementine (@clementinemorrigan).2020. "Accountability does not mean allowing our boundaries to be crossed." Instagram post, April 10, 2020, https://www.instagram.com/p/B-zddIrAYFo/?igshid=18ig6mt4z01 $4 d$

Nussbaum, Martha. 2016. Anger and Forgiveness: Resentment, Generosity, Justice. New York, NY: Oxford University Press.

Oakley, Be. 2018. "On Failure.” In Gender Fail - An Anthology on Failure 1, edited by Be Oakley, 6-11. Brooklyn, NY: GenderFail.

Powell, Walter W. and DiMaggio, Paul J., eds. 1991. The New Institutionalism in Organizational Analysis. Chicago: The University of Chicago Press, 1991.

Quinn, Therese. 2020. School: Questions about Museums, Culture And Justice to Explore in Your Classroom. New York: Teachers College Press.

Ranta, Kukka and Kanninen, Jaana. 2019. Vastatuuleen. Saamen kansan pakkosuomalaistamisesta. Helsinki: S\&S.

Thom, Kai Cheng. 2019. I Hope We Choose Love: A Trans Girl's Notes From The End of The World. Vancouver: Arsenal Pulp Press.

Vadén, Tere. 2016. "Modernin yksilön harhat ja ympäristötaidekasvatus." In Taidekasvatus ympäristöhuolen aikakaudella — avauksia, suuntia, mahdollisuuksia, edited by Anniina Suominen, 134-141. Espoo: Aalto ARTS Books.

Wynn, Natalie. 2020. “Canceling." Published January 2, 2020 on Contrapoints Youtube channel. Video, 1:40:27. https://www.youtube.com/ watch? $\mathrm{v}=\mathrm{OjMPJVmXxV8.}$ 